\section{Accelerated onset of vecuronium neuromuscular block with pulmonary arterial administration}

Hiroshi Iwasaki MD, Motohiko Igarashi MD, Shin Kawana MD, Akiyoshi Namiki MD
The purpose of this study was to determine the onset times of vecuronium neuromuscular block administered into either the central circulation or a peripheral vein. One hundred and twenty adult patients with a pulmonary artery $(P A)$ catheter were randomly divided into one of three groups with respect to the routes of vecuronium administration ( $n=40$ in each group). Anaesthesia was induced with midazolam $2.5 \mathrm{mg}$ iv and fentanyl 10-50 $\mu \mathrm{g} \cdot \mathrm{kg}^{-1} \dot{\mathrm{N}}$ and maintained with intermittent doses of fentanyl $50 \mu \mathrm{g} i \mathrm{v}$ and nitrous oxide $60-70 \%$ in oxygen. After immobilization of the forearm in a splint, the ulnar nerve was stimulated supramaximally every $12 \mathrm{sec}$. The resulting force of the evoked thumb twitch was recorded (Myograph 2000, Biometer, Denmark). The times from the injection to the first depression of $t$ witch response (latent onset) in patients given vecuronium $0.08 \mathrm{mg} \cdot \mathrm{kg}^{-1}$ into the pulmonary artery, the right atrium, and a peripheral vein on the hand were $58.0 \pm 19.5,71.5 \pm 17.1$, and $82.4 \pm 18.0 \mathrm{sec}$ (mean \pm $S D)$, respectively. The latent onset of neuromuscular block occurred sooner in patients given vecuronium into the central vein than when administered into a vein on the hand $(P<$ $0.01)$. In comparing the patients given vecuronium into the central vein, the onset times to $95 \%$ twitch depression (onset) were $152.3 \pm 40.7$ and $168.2 \pm 35.5$ sec. The onset of block was found to be faster when vecuronium was administered into the pulmonary artery than into the right atrium $(P<0.01)$. These findings suggest that the administration of vecuronium into the pulmonary artery is one approach to accelerate neuromuscular blockade in patients with a $P A$ catheter.

\section{Key words}

NEUROMUSCULAR RELAXANTS: onset, vecuronium.

From the Department of Anesthesiology, Sapporo Medical University, School of Medicine, Sapporo, Japan 060.

Address correspondence to: Dr. H. Iwasaki, Department of Anesthesiology, Sapporo Medical University, School of Medicine, South-1, West-16, Chuoku, Sapporo, Japan 060. Accepted for publication 1lth Aug, 1994.
Cette étude vise à déterminer la rapidité dinstallation du bloc neuromusculaire au vécuronium administré soit dans la circulation centrale, soit dans une veine périphérique. Cent vingt patients porteurs d'un cathéter artériel pulmonaire sont répartis au hasard en trois groupes caractérisés par la voie d'administration ( $n=40$ pour chaque groupe). L'anesthésie est induite au midazolam $2,5 \mathrm{mg}$ iv et au fentanyl $10-50 \mu \mathrm{g} \cdot \mathrm{kg}^{-1}$ et entretenue avec des doses intermittentes de fentanyl $50 \mu \mathrm{g}$ iv et du protoxyde d'azote 60-70\% en oxygène. Après l'immobilisation de lavant-bras dans une attelle, un stimulation supramaximale est appliquée au nerf cubital à toutes les 12 sec. La force de la contraction du pouce est enregistrée (Myograph 2000, Biometer, Danemark). Lintervalle entre l'injection unique de $0,08 \mathrm{mg} \cdot \mathrm{kg}^{-1}$ et la dépression du premier twitch (intervalle de latence) administrée dans l'artère pulmonaire, l'oreillette droite et une veine périphérique de la main sont de 58,0 \pm $19,5,71,5 \pm 17,1$ et $82,4 \pm 18,0 \mathrm{sec}$ (moyenne $\pm S D$ ) respectivement. Lintervalle de latence du block neuromusculaire est plus courte chez les patients qui reçoivent le vécuronium dans une veine centrale que dans une veine de la main ( $P$ $<0,01)$. Lorsqu'on compare les patients qui ont reçu le vécuronium par une veine centrale, lintervalle à $95 \%$ de la dépression du twitch est de 152,3 $\pm 40,7$ et de 168,2 $\pm 35,5 \mathrm{sec}$. La vitesse dinstallation du block est plus rapide quand le vécuronium est administré dans l'oreillette droite $(P<0,01)$. Ces données portent à croire que l'administration de vécuronium dans l'artère pulmonaire accélère le bloc neuromusculaire chez les porteurs de cathéters artériels pulmonaires.

One of the aims in the research of neuromuscular blocking drugs is to find a non-depolarizing relaxant with a rapid onset of action. Muscle relaxants are usually administered into a peripheral vein, and carried to the central circulation where they mix with venous blood coming from all organs and proceed to their site of action via the blood stream. Thus, the time lapse between the administration of a non-depolarizing relaxant and the onset of its neuromuscular blocking effect is modified by the transition time from a peripheral vein to the central cir- 
culation.' Although this is generally accepted, there' is little information about the onset of neuromuscular blockade following the administration of vecuronium into the central circulation.

The purpose of this study was to evaluate whether the administration of vecuronium into the pulmonary artery accelerated the onset of neuromuscular blockade.

\section{Methods}

With approval from our Human Research Committee and informed consent, 120 patients scheduled for elective cardiac surgery (coronary artery bypass graft $n=51$; valve replacement $n=69$ ) aged 17-75 yr (average 58.2) and weighing 43-75 $\mathrm{kg}$ (average 57.3) were studied. In all, pulmonary artery (PA) catheters were inserted preoperatively. None had neuromuscular disorders or were receiving any drug known to affect neuromuscular function. The patients were premedicated with midazolam $2.5 \mathrm{mg}$ im and either atropine $0.5 \mathrm{mg}$ or scopolamine $0.4 \mathrm{mg}$ im one hour before induction of anaesthesia.

Before induction of anaesthesia, the arm was immobilized in a standardized manner using a splint, and the thumb was attached to a force displacement transducer, in order to measure isometric contractions of the adductor pollicis. Anaesthesia was induced with midazolam $2.5 \mathrm{mg}$ $\dot{\nu}$ and maintained with fentanyl $10-50 \mu \mathrm{g} \cdot \mathrm{kg}^{-1}$ and nitrous oxide $60-70 \%$ in oxygen administered by face mask. Ventilation was controlled manually to keep $\mathrm{PETCO}_{2}$ within the range of 35 to $40 \mathrm{mmHg}$.

After steady state anaesthesia was established for at least ten minutes, the patients were randomly assigned to one of three treatment groups with respect to the routes of vecuronium administration ( $n=40$ in each group). Groups 1 and 2 were given vecuronium, $0.08 \mathrm{mg} \cdot \mathrm{kg}^{-1}$, into the PA and the right atrium through the PA catheter, respectively, and Group 3 was given the same amount through an indwelling cannula on the dorsum of the hand. The PA catheter and the cannula were flushed with $5 \mathrm{ml}$ of saline immediately after vecuronium administration. Arterial blood pressure and heart rate were continuously measured through a cannula placed in the radial artery during the study.

Neuromuscular block was evaluated every $12 \mathrm{sec}$ by measuring the force-of-thumb-adduction produced in response to supramaximal stimulation of the ulnar nerve with repetitive train-of-four using surface electrodes at the wrist. The force-of-thumb adduction was recorded (Myograph 2000, Biometer, Denmark). The resting tension applied to the thumb was adjusted to $200 \mathrm{~g}$. In Group 3, neuromuscular block was monitored in contradicted hand from that receiving vecuronium.

Immediately after the administration of vecuronium, the PA catheter was utilized to measure cardiac output
TABLE I Patient characteristics. There were no differences between the groups. All data are represented as mean \pm SD

\begin{tabular}{|c|c|c|c|c|}
\hline & $\begin{array}{l}\text { Sex } \\
(M / F)\end{array}$ & $\begin{array}{l}\text { Age (yr) } \\
\text { (range) }\end{array}$ & $\begin{array}{l}\text { Height }(\mathrm{cm}) \\
\text { (range) }\end{array}$ & $\begin{array}{l}\text { Weight (kg) } \\
\text { (range) }\end{array}$ \\
\hline Group 1 & $22 / 18$ & $\begin{array}{l}61.1 \pm 12.1 \\
(17-73)\end{array}$ & $\begin{array}{l}160.1 \pm 10.2 \\
(145-176)\end{array}$ & $\begin{array}{l}58.2 \pm 7.8 \\
(47-72)\end{array}$ \\
\hline Group 2 & $18 / 22$ & $\begin{array}{l}59.5 \pm 9.6 \\
(37-75)\end{array}$ & $\begin{array}{l}158.9 \pm 9.3 \\
(143-187)\end{array}$ & $\begin{array}{l}57.1 \pm 8.9 \\
(45-75)\end{array}$ \\
\hline Group 3 & $19 / 21$ & $\begin{array}{l}55.4 \pm 11.8 \\
(22-69)\end{array}$ & $\begin{array}{l}159.0 \pm 9.3 \\
(145-172)\end{array}$ & $\begin{array}{l}57.5 \pm 10.3 \\
(43-74)\end{array}$ \\
\hline
\end{tabular}

TABLE II Candiac index and onset time following administration of vecuronium $0.08 \mathrm{mg} \cdot \mathrm{kg}^{-1}$ into the pulmonary artery (Group 1), right atrium (Group 2), or peripheral vein on the hand (Group 3). All data represent mean $\pm \mathrm{SD}$

\begin{tabular}{llll}
\hline & $\begin{array}{l}\text { Cardiac index } \\
\left(L \cdot \mathrm{min}^{-1} \cdot \mathrm{m}^{-2}\right)\end{array}$ & $\begin{array}{l}\text { Latent onset } \\
\text { time }(\mathrm{sec})\end{array}$ & $\begin{array}{l}\text { Time to 95\% } \\
T_{1} \text { depression } \\
(\mathrm{sec})\end{array}$ \\
\hline Group 1 & $3.18 \pm 1.15$ & $58.0 \pm 19.5$ & $152.3 \pm 40.7$ \\
Group 2 & $2.94 \pm 1.83$ & $71.5 \pm 17.1$ & $168.2 \pm 35.5^{*}$ \\
Group 3 & $3.18 \pm 1.15$ & $82.4 \pm 18.0 \dagger$ & $191.7 \pm 33.5 \dagger$ \\
\hline
\end{tabular}

$* P<0.01$ vs Group 1 .

$\dagger P<0.01$ vs Groups 1 and 2 .

using $10 \mathrm{ml}$ of iced $5 \%$ dextrose in all patients. The average of three injections was used to calculate the cardiac index.

The degree of neuromuscular block was measured as the decrement in contractile response of the first response $\left(T_{1}\right)$, relative to control. The times from vecuronium injection to the first depression of $T_{1}$ (latent onset time) and to depression of $T_{1}$ to $5 \%$ of control (onset time) to ulnar nerve stimulation were recorded.

Data were analyzed statistically by ANOVA, followed by Student's $t$ test. $P<0.05$ was considered significant. Data were expressed as mean \pm standard deviation.

\section{Results}

The three groups of patients did not differ in weight, height, age, or cardiac index (Table I). The onset of fade in train-of-four responses was more rapid in Group I (PA administration) than in Groups 2 (right atrial administration) and 3 (peripheral vein administration) $(P<0.01)$. Patients administered vecuronium into a peripheral vein (Group 3) took longer time to produce 95\% T1 depression $(P<0.01)$. However, no significant differences in this index were demonstrated between Groups 1 and 2 (Table II).

The mean times of onset of neuromuscular blocking action after vecuronium in the three groups were not 
different between patients with and without cardiac valve disease. There were no changes in heart rate or arterial pressure in any patient.

\section{Discussion}

This study demonstrates that the route of vecuronium administration affects the onset of neuromuscular blockade in the peripheral muscles. The onset of neuromuscular blockade in the adductor pollicis muscles occurred more rapidly in patients given vecuronium into the central circulation than in patients given the drug into a peripheral vein on the hand. In comparing the patients administered vecuronium into the central circulation, no differences in the time of vecuronium injection to the start of relaxant action were demonstrated. However, times from injection to $95 \%$ depression of twitch response were more rapid in patients given vecuronium into the pulmonary artery than in those administered the drug into the right atrium.

In clinical practice, muscle relaxants are commonly administered into a peripheral vein on the hand. The drugs are carried through the pulmonary circulation, the left side of the heart, the aorta and finally to the neuromuscular junction. Thus, the transit time required for peripheral blood to enter the central circulation may influence the onset of neuromuscular blockade. This period is made up, to a large extent, by the circulation time. It has been reported that the peripheral vein-to-artery circulation time is $10-30 \mathrm{sec}$, although these values are influenced by cardiac output. ${ }^{2,3}$ In the present study, the reason for the rapid onset of neuromuscular blockade observed in the patients receiving vecuronium into the central circulation can be explained because more drug reaches the limb more quickly from that location, producing a rapid peak plasma concentration.

Acceleration of the onset of paralysis produced by nondepolarizing relaxants is advantageous in clinical practice. If the accelerated depression of muscle activity is accompanied by easier intubating conditions, non-depolarizing relaxants could be used in emergency conditions when succinylcholine is contraindicated. Vecuronium is associated with a relatively slow onset, particularly when compared with succinylcholine.

Various methods such as "priming ${ }^{n 4}$ and larger doses 5 have been tried to reduce the delay before neuromuscular blockade. However, using these techniques, some patients have experienced subjective weakness or demonstrate prolonged neuromuscular action with the larger doses. Our results with standard doses of vecuronium injected into the central circulation may provide an alternative means of achieving a rapid onset of neuromuscular blockade, allowing earlier tracheal intubation.

In conclusion, the administration of vecuronium into the central vein provides a more rapid onset of neuromuscular blockade.

\section{References}

1 Harrison GA, Junius $F$. The effect of circulation time on the neuromuscular action of suxamethonium. Anaesth Intensive Care 1972; 1: 33-40.

2 Gramstad L, Lilleaasen P, Minsaas B. Onset time and duration of action for atracurium. ORG NC45 and pancuronium. Br J Anaesth 1982; 54: 827-30.

3 Upton RN, Huang $Y F$. Influence of cardiac output, injection time and injection volume on the initial mixing of drugs with venous blood after i.v. bolus administration to sheep. Br J Anaesth 1993; 70: 333-8.

4 Schwarz S, Ilias W, Lackner F, Mayrhofer O, Foldes FF. Rapid tracheal intubation with vecuronium: the priming principle. Anesthesiology 1985; 62: 388-91.

5 Ginsberg B, Glass PS, Quill T, Shafron D, Ossey KD. Onset and duration of neuromuscular blockade following high-dose vecuronium administration. Anesthesiology 1989; 71: 201-5. 